\title{
Features of the joint work of structures and pile foundations on loess foundations
}

\author{
Zakiryo Buzrukov*, Ilkhom Yakubjanov, and Mukhtorzhon Umataliev \\ Namangan Engineering Construction Institute, Namangan, Uzbekistan
}

\begin{abstract}
This paper presents the results of using frame structures in industrial construction with pile foundations under dynamic influences. In the course of the study, a set of formulas were derived to determine the amplitude-frequency characteristics of the system "flat frame-grillagegroup of piles" at different levels of action of loads excited from the seismic platform, and natural frequencies were calculated, bending moments, shear forces at the points of fixation of the system elements were determined. The results of calculations and analysis make it possible to obtain the dynamic characteristics of a flat frame on pile foundations, which are necessary for subsequent calculations.
\end{abstract}

\section{Introduction}

Design and construction of buildings and structures on collapsible soils to ensure their strength and normal operation are among the most important and complex problems of modern construction. This problem is especially relevant in the conditions of Uzbekistan, where subsidence soils have a high thickness, are widespread almost everywhere, and are the main type of soil conditions.

Improving the efficiency and quality of construction largely depends on the correct assessment of the properties of soil foundations and the choice of foundations for buildings and structures. Particular difficulties arise in the design of buildings and structures on loess subsidence soils, which occupy about $35 \%$ of the area on the territory of Uzbekistan, common almost everywhere. The reliable erection of buildings on these soils is one of the most difficult problems of modern construction.

The experience of operating buildings and structures on loess collapsible soils shows that the properties of these soils and their behavior under load and soaking have not been studied enough. Only in recent years, many buildings located in our Republic have been in a deformed state. The main factors causing the emergency state of buildings and structures are flooding of urban areas, uneven subsidence of the foundation, errors during engineering and geological surveys, non-compliance with technical conditions for the production of construction and installation works, etc. [7-14].

All this indicates that the problem of ensuring the stability and reliability of buildings and structures on loess subsiding soils has not been fully resolved. There are significant drawbacks of the existing design models for the design of structures on soils of this type,

*Corresponding author: zsbuzrukov@mail.ru 
which do not take into account the specifics of the engineering and geological structure of loess rocks, their structural and textural features, and the physical and mechanical characteristics of the construction site [4-6].

Loess rocks, which occupy a significant part of our Republic, are confined to the most intensive economic development regions, and a significant part of this territory belongs to earthquake-prone regions. In Uzbekistan, loess rocks cover the central and eastern parts of the territory. These areas are the most dangerous in terms of seismicity. Thus, considering several specific properties inherent in loesses (first of all, subsidence), designers and builders face the difficult task of ensuring the bearing capacity of loess foundations and the seismic resistance of buildings and structures erected on them [3].

The development of the modern industry is accompanied by a significant increase in the power of industrial installations - sources of oscillations and their increasing concentration at industrial sites.

Waves, propagating over a distance of hundreds and thousands of kilometers in soils from sources of disturbance, cause vibrations of buildings and structures.

The damage from this situation is so great that the vibration barrier has become one of the most important environmental problems.

The damping properties of pile foundations play a significant role in reducing the dynamic loads originating from industrial sources, transmitted to the ground structures of such buildings and structures classified as structures with a rigid structural scheme.

However, the study of vibrations of structures and the calculation of buildings and structures interacting with subsiding soils have not been sufficiently studied.

Failure to consider the joint work of structures with subsiding soils leads to the loss of stability of the foundations and the destruction of structures. To prevent these phenomena and the complexity of the system, "structures - foundation - soil" is relevant to conduct experimental and field studies of buildings and structures, including improving methods for calculating buildings under dynamic loads [1,2].

One of the main tasks of calculating structures for dynamic loads is the determination of displacements, shear forces, bending moments, etc. It follows from this that a complete analysis of buildings and structures during forced vibrations, depending on the geometric physical parameters, the system creates sufficient conditions for their further operation under unfavorable conditions.

There is the considering the relevance of the use of frame structures in industrial construction with pile foundations under dynamic influences. This article deals with the problem of joint vibration of the pile foundation, columns, and floors working as a whole.

The research object is a one-story industrial building consisting of a flat frame on pile foundations (Figure 1). 


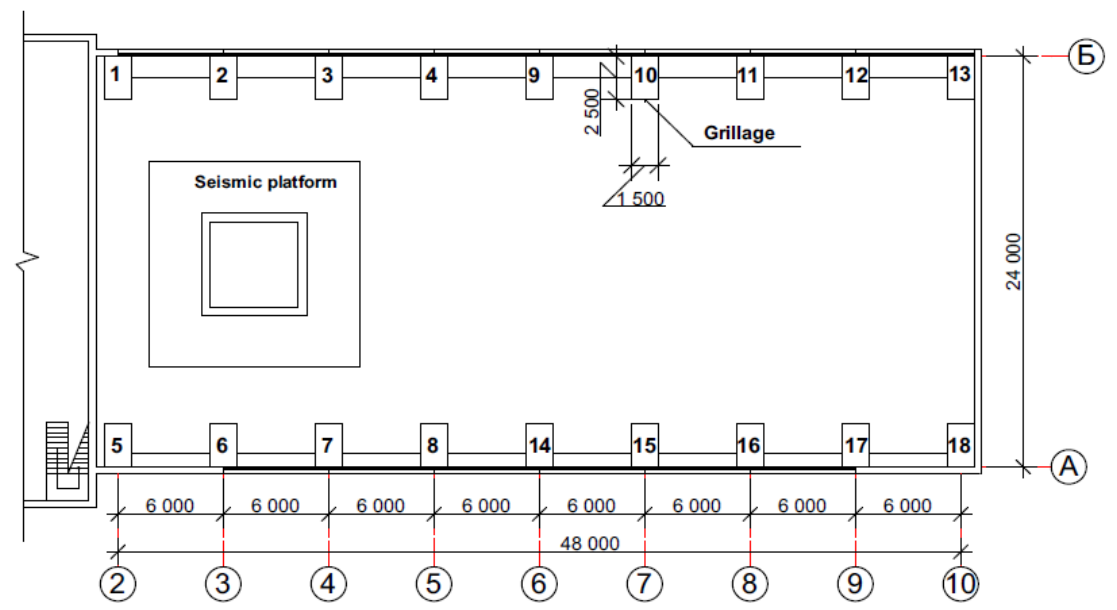

Fig. 1. Layout of grillages, columns, and seismic platform of a one-story industrial building

In this case, we consider two different sides of the problem to be solved:

a) Grillage operate independently from each other;

b) The grillage connecting the pile heads works in the form of a solid slab.

The problem of dynamic calculation of the system "flat frame-grillage-pile group" can be formulated as follows: calculate natural frequencies, determine bending moments, shear forces at the fixing points of the system elements, obtain the amplitude-frequency characteristics of the system at different levels of action of loads excited from the seismic platform and at separate work of grillages uniting the heads of piles, including in the position of their fastening (grillages) to a single slab.

\section{Methods}

First, we will study the first task. For the general solution of the problem with forced vibrations of the system, we proceed from the following differential equation

$$
\mathrm{E}_{\mathrm{s}} \mathrm{J}_{\mathrm{s}} \frac{\partial^{4} \mathrm{~W}_{\mathrm{kc}}^{(\mathrm{n})}}{\partial \mathrm{x}^{4}}+\mathrm{m}_{\mathrm{s}} \frac{\partial^{2} \mathrm{~W}_{\mathrm{kc}}^{(\mathrm{n})}}{\partial \mathrm{t}^{2}}+\mathrm{k}\left(\mathrm{W}_{\mathrm{kc}}^{(\mathrm{n})}-\mathrm{W}_{\mathrm{pl}}\right)=0
$$

Using dimensionless parameters and some transformations, equation (1) is written in the following form

$$
\frac{\partial^{4} \mathrm{Y}_{\mathrm{kc}}^{(\mathrm{n})}}{\partial \xi^{4}}+\frac{\partial^{2} \mathrm{Y}_{\mathrm{kc}}^{(\mathrm{n})}}{\partial \tau^{2}}+\beta\left(\mathrm{Y}_{\mathrm{kc}}^{(\mathrm{n})}-\mathrm{Y}_{p l}\right)=0, \mathrm{k}=\overline{1, \overline{6}}
$$

where $Y_{k c}^{(n)}$ is displacement of the k- pile belonging to the $\mathrm{n}$ - grillage.

We seek the solution to equation (2) in the following form

$$
\mathrm{Y}_{\mathrm{kc}}^{(\mathrm{n})}=\mathrm{V}_{\mathrm{on}}\left[\left(\frac{\xi}{\eta_{2}}\right)^{3} \mathrm{a}_{3}+\left(\frac{\xi}{\eta_{2}}\right)^{2} \mathrm{a}_{2}+\left(\frac{\xi}{\eta_{2}}\right) \mathrm{a}_{1}+\mathrm{a}_{0}\right]+\mathrm{Y}_{\mathrm{kc}}^{(\widetilde{\mathrm{n})}(\xi, \tau)}
$$

Here $a_{0}, a_{1}, a_{2}, a_{3}$ are unknown constants determined from the boundary conditions. After transformations (3), we obtain the following form 


$$
\mathrm{Y}_{\mathrm{kc}}^{(\mathrm{n})}=\mathrm{V}_{\mathrm{on}}\left[3\left(\frac{\xi}{\eta_{2}}\right)^{2}-2\left(\frac{\xi}{\eta_{2}}\right)^{3}\right]+\mathrm{Y}_{\mathrm{kc}}^{(\overline{\mathrm{n})}(\xi, \tau)}
$$

Taking into account the accepted condition, Eq. (4) write

$$
\frac{\partial^{4} \mathrm{Y}_{\mathrm{kc}}^{(\mathrm{n})}}{\partial \xi^{4}}+\frac{\partial^{2} \mathrm{Y}_{\mathrm{kc}}^{(\mathrm{n})}}{\partial \tau^{2}}-\left[3\left(\frac{\xi}{\eta_{2}}\right)^{2}-2\left(\frac{\xi}{\eta_{2}}\right)^{3}\right]\left(\ddot{\mathrm{V}_{0 \mathrm{n}}}+\beta \mathrm{V}_{0 \mathrm{n}}\right)+\beta \mathrm{V}_{p l}
$$

Now we write the differential equation of oscillations of individual grillages with numbers $n=\overline{1,8}$ and $n=\overline{9,18}$

$$
\begin{gathered}
\ddot{\mathrm{V}_{0 \mathrm{n}}}=-\rho \sum_{\mathrm{k}=1}^{6} \frac{\partial^{3} \mathrm{Y}_{\mathrm{kc}}^{(\mathrm{n})}}{\partial \xi^{3}}+\delta_{1 \mathrm{c}} \rho_{1} \frac{\partial^{3} \mathrm{Y}_{\mathrm{n}}}{\partial \xi^{3}}+\beta \gamma_{\mathrm{c}}\left(\mathrm{Y}_{p l}-\mathrm{V}_{0 \mathrm{n}}\right), n=\overline{1,8}(6) \\
\ddot{\mathrm{V}_{0 \mathrm{n}}}=-\rho \sum_{\mathrm{k}=1}^{6} \frac{\partial^{3} \mathrm{Y}_{\mathrm{kc}}^{(\mathrm{n})}}{\partial \xi^{3}}+\delta_{1 \mathrm{c}} \gamma_{\mathrm{c}} \frac{\partial^{3} \mathrm{Y}_{\mathrm{n}}}{\partial \xi^{3}}, n=\overline{9,18}
\end{gathered}
$$

The approximating function of the displacement of the platform, pile, columns, grillage, and coverings is given in the following form

$$
\begin{gathered}
Y_{p l}=\alpha_{0} \sin \alpha \tau, Y_{k c}=\alpha_{k c}(\xi) \sin \alpha \tau, Y_{n}=\alpha_{n}(\xi) \sin \alpha \tau, V_{o n}=\beta_{o n}(\xi) \sin \alpha \tau, \\
V_{1}=\beta_{1} \sin \alpha \tau
\end{gathered}
$$

Based on the above equations, we finally determine the displacements of floors and grillages of the system "flat frame-grillage-pile group."

$$
\begin{gathered}
\beta_{1}=\frac{\theta_{19}}{\theta_{18}} \\
\beta_{\text {on }}=-\beta_{1} \delta_{1 c} \rho_{1} \frac{\theta_{11}}{\theta_{14}}+\frac{\theta_{15}}{\theta_{14}}, \\
\beta_{\text {on }}=-\beta_{1} \delta_{1 c} \rho_{1} \frac{\theta_{11}}{\theta_{16}}+\rho_{1} \frac{\sum_{n=1}^{6} \theta_{6}}{\theta_{16}}, \quad n=\overline{9,18}
\end{gathered}
$$

where: $\theta_{6}, \theta_{11}, \theta_{14}, \theta_{15}, \theta_{16}, \theta_{18}, \theta_{19}$ is received designation.

Figure 1-6 shows graphs of changes in the magnitude of displacements of coatings, grillages, including changes in the magnitude of shearing forces and bending moment along the height of the pile and the column of the "flat frame-grillage-group of piles" system.

At the second stage, we will consider the work of grillages, which, by combining the heads of the piles, work in the form of a solid monolithic slab.

For this case, we write down the differential equation of vibrations of the pile foundation in the following form

$$
\begin{aligned}
& \frac{\partial^{4} \mathrm{Y}_{\mathrm{kc}}^{(\mathrm{n})}}{\partial \xi^{4}}+\frac{\partial^{2} \mathrm{Y}_{\mathrm{kc}}^{(\mathrm{n})}}{\partial \tau^{2}}+\beta\left(\mathrm{Y}_{\mathrm{kc}}^{(\mathrm{n})}-\mathrm{Y}_{p l}\right)=0, \quad \mathrm{k}=\overline{1,4} \\
& \frac{\partial^{4} \mathrm{Y}_{\mathrm{kc}}^{(\mathrm{n})}}{\partial \xi^{4}}+\frac{\partial^{2} \mathrm{Y}_{\mathrm{kc}}^{(\mathrm{n})}}{\partial \tau^{2}}+\beta \mathrm{Y}_{\mathrm{kc}}^{(\mathrm{n})}=0, \quad \mathrm{k}=\overline{5,9}
\end{aligned}
$$

By solving equations (11) and (12), similarly to formula (3), one can write

$$
\mathrm{Y}_{\mathrm{kc}}^{(\mathrm{n})}=\mathrm{V}_{\mathrm{o}}\left[\left(\frac{\xi}{\eta_{2}}\right)^{3} \mathrm{a}_{3}+\left(\frac{\xi}{\eta_{2}}\right)^{2} \mathrm{a}_{2}+\left(\frac{\xi}{\eta_{2}}\right) \mathrm{a}_{1}+\mathrm{a}_{0}\right]+\mathrm{Y}_{\mathrm{kc}}^{(\overline{\mathrm{n})}(\xi, \tau)}
$$

where: $V_{\mathrm{o}}$ is the movement of the solid plate (combined grillages)

Based on formulas (11), (12) and solutions of equations (13), making several transformations, we finally obtain the displacements of the coatings and the solid slab of the uniting heads of the piles 


$$
\begin{aligned}
& \beta_{1}=\frac{\theta_{20}}{\theta_{19}} \\
& \beta_{o n}=-\beta_{1} \delta_{1 c} \rho_{1} \frac{\sum_{n=1}^{9} \theta_{13}}{\theta_{16}}+\frac{\theta_{17}}{\theta_{16}},
\end{aligned}
$$

where: $\theta_{13}, \theta_{16}, \theta_{17}, \theta_{19}, \theta_{20}$ is received designation.

\section{Results and Discussion}

Based on the obtained formulas, graphs were built to determine the magnitude of displacements of coatings, combined grillages, and graphs of changes in the magnitude of the shearing force and bending moment at the ends of the elements of the system.

From the graph of the change in the magnitude of the displacements of the coatings (Figure 1), it can be seen that the first resonance occurs at a frequency of $\alpha=1$, and the second resonance at a frequency of $\alpha=4$. With an increase in frequency, the displacements of the coatings decrease. Here, the coating made as a single flat disk on its work no obstacle exists.

Figure 2 shows the magnitude of the movements of the grillage $n=\overline{1,8}$ and $n=\overline{9,18}$ differs from Fig. 1 only in its value, and the law of change is the same. This indicates the resonant frequencies of the coated grillages are almost the same.

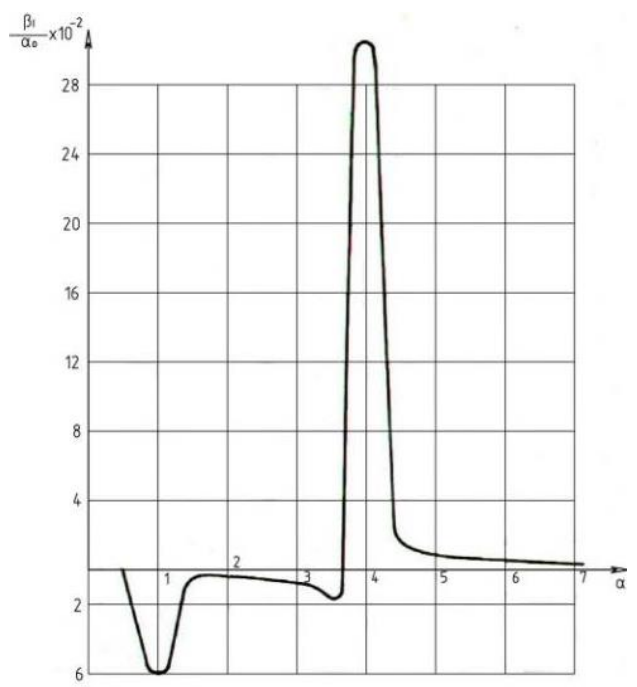

Fig. 2. Graph of changes in the magnitude of displacement of coatings

Including obtained curves of changes in the magnitude of the shearing force at the upper boundary of the pile, at the lower and upper ends of the frame post. The pattern of all curves is almost the same, and resonance phenomena occur at a frequency of $\alpha=4$. Further, the value of the shearing force gradually increases.

The nature of the increase in the value of the bending moment at the upper boundary of the pile indicates that with increasing frequency, the value of the bending moment increases, which means resonance does not occur.

In the course of calculating based on the obtained graphs of the dependence of the change in the magnitude of the bending moment and shearing forces along the height of the pile and the column of the system "flat frame-grillage-group of piles," it was seen that the maximum bending moment is found at mark $\xi=0,78$, and at the ends ( at the mark 
$\xi=1$ ) of the column, it is equal to zero, since, here, the column with trusses has a hinge fixation.

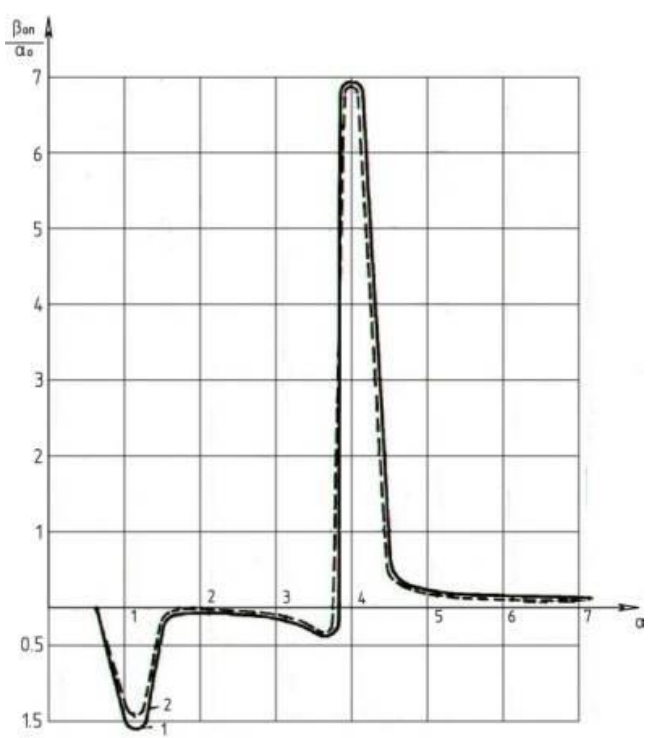

Fig. 3. Graph of changes in the magnitude of movements of grillages. 1-grillages with number; 2grillage with number

An analysis of the graphs obtained shows that if the grillages work separately, their displacement value is less than that of the combined grillages.

From the graphs obtained, the change in the magnitude of the displacements of the combined grillages, it was seen that the first and second resonances correspond at a frequency of $\alpha=1$ and $\alpha=3.5$, and the last resonance occurs at a frequency of $\alpha=4$. The nature of the curve with the graph of changes in the amplitude of displacements of individual grillages is almost similar. From this, it follows that the maximum value of the displacements of individual grillages and grillage plates are close to each other.

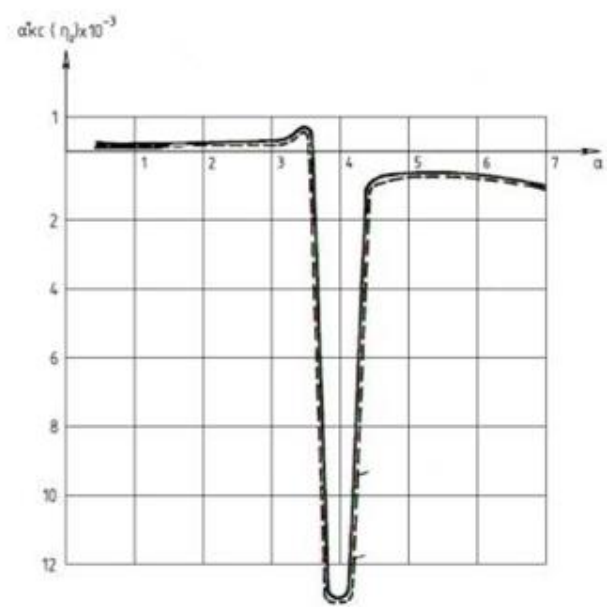

Fig.4. Graph of the change in the shear force at the top of the pile. 1-piles with number; 2-piles with number 
The difference in the values of the shearing force at the upper boundary of the piles $n=$ $\overline{1.4}$ and $n=\overline{5.9}$ is very large. For piles $n=\overline{1.4}$ at a frequency of $\alpha=3.5$ the first resonance enters, and the second at $\alpha=4$, then decreasing the value of the efforts to a frequency of $\alpha=4.5$ begins to gradually increase. For piles $n=\overline{5.9}$ we can assume that at a frequency of $\alpha=3.5$, one resonance phenomenon occurs. At a frequency of $\alpha=4$ the effort, assuming its zero value begins to gradually increase. This can be explained by the fact that the initial piles with the number $n=\overline{1.4}$ working under the combined grillages, receive much more load from the seismic platform due to their proximity.

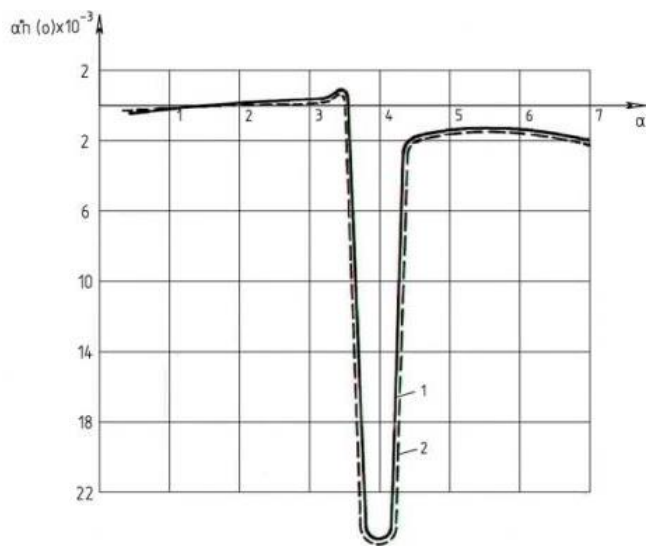

Fig. 5. Graph of shear force change at the lower end of the frame post. 1-stands with a number; 2racks with number

The nature of the change in the magnitude of the shearing force at the lower and upper ends of the frame strut is almost the same. At frequencies $\alpha=1$ (at the upper end), $\alpha=3,5$ and $\alpha=4$ the efforts take their maximum values. In the range of maximum frequencies after $\alpha=4$ the efforts begin to gradually increase.

At the upper boundary of the pile, the bending moment at a frequency of $\alpha=1$ is maximized. Further, at a frequency of $\alpha=3,5$ getting its second large value, at $\alpha=4$ it is equal to zero, with an excess of frequency, it begins to gradually increase.

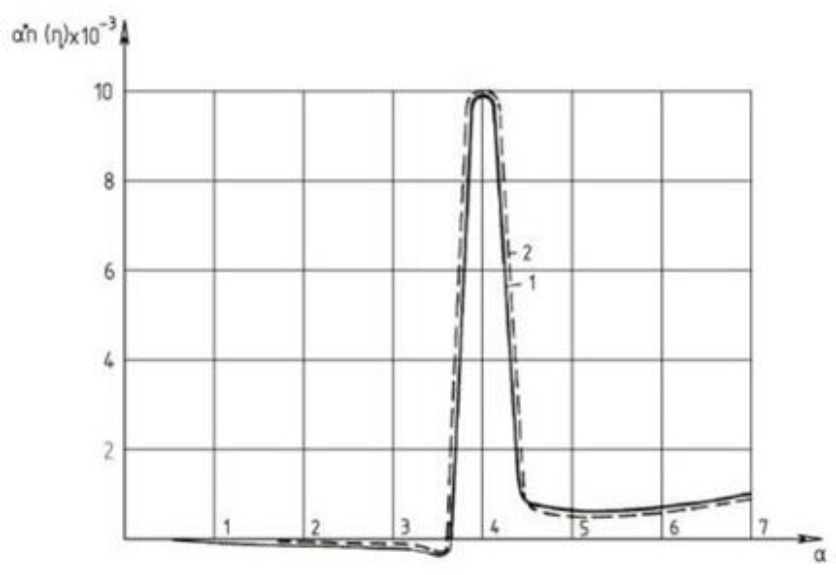

Fig.6. Graph of shear force change at the top end of the frame strut. 1-stands with a number; 2-racks with number 
From the graph of the change in the magnitude of the bending moment at the lower end of the frame strut, it can be judged that at the lower end of the frame strut, the bending moment is almost rectilinear, only at a frequency of $\alpha=6,5$ it takes a very small value.

\section{Conclusions}

Based on the analysis of the results of theoretical and field studies of the vibrations of the selected structures working with pile foundations, the following conclusions can be drawn:

- based on theoretical calculations, differential equations are derived that describe the determination of bending moments, shearing forces at the fixing points of the elements of the system "flat frame - grillage-pile group" under dynamic influences;

- to determine the reliability of the theoretical calculation based on formulas (8-10), (14), (15), the results are compared with experimental data;

- resonance curves obtained from field data were constructed using the "fixed frequency" method, ensuring the accuracy of the results;

- a comparison of the curves shows that the nature of the change in the amplitude of the oscillations of the selected points of the columns from the frequency is qualitatively close to each other. The discrepancy near the resonant frequency is about $15 \%$. The resonant amplitude, according to field data, is achieved at lower frequencies than theoretical.

- compared theoretical and experimental data of the frequency response obtained for a certain grillage. On this grillage, the maximum oscillation amplitude coincides very closely with each other. An increase in frequency, in both cases, leads to a decrease in the amplitude of the grillage oscillations. The discrepancy between theoretical and experimental values is about $16 \%$.

- The proposed method for calculating the system "flat frame - grillage-pile group" under dynamic influences allows you to identify and use additional reserves of structural strength and thereby design this structure with a high degree of reliability, which leads to a decrease in loads, as a result, to saving building materials and labor costs.

\section{References}

1. Buzrukov Z., and Khamrakulov A. Joint work of a flat frame and pile foundations under dynamic impacts. 2nd International Conference on Robotics and Mechantronics. IOP Conf. Series: Materials Science and Engineering 517 (2019) 011001.

2. Buzrukov Z.S. Selection of the design scheme of the system "flat frame-grillage-pile group" under dynamic load. UNIVERSIUM, № 12(81), pp. 86-92. Moscow, (2020)

3. Buzrukov Z.S. Features design of foundations of high-rise buildings, taking into account soil conditions, "Bulletin of Science and Education", № 22 (100). pp.79-86. Moscow, (2020)

4. Klepikov S.N., Tregub A.S., and Matveev I.V. Calculation of buildings and structures on subsidence soils, pp. 200. Kiev, (1987)

5. Shvetsov G.I., Noskov I.V. Loess collapsible soils of Western Siberia, their engineering-geological, geoecological properties and their change under the influence of technogenic impacts, Reports of the plenary session of the International Scientific and Practical Conference "Loess collapsible soils: research, design, construction", pp. 3-25, Barnaul, (1997) 
6. Voznesensky E.A. Dynamic instability of soils, Bulletin of Moscow University, 4, Geology, № 5. pp.71-88, (1995)

7. Khasanov A.Z., Strigo G.S., Mustakimov V.R. Deformations of brick buildings on subsidence grounds of the Zeravshan oasis, Foundations, foundations and soil mechanics, № 6, pp.23-26, (1993)

8. Bolshakov V.I., Motorny A. N. Motorny A. Analysis of the existing design schemes and the choice of optimal solutions for the scheme of work of piles in clay soils, Bulletin of the Pridneprovsk state academy of engineering and architecture. № 9 (222). pp.10-21, (2016)

9. Alimov H.L., Buzrukov Z.S. Methodology for experimental studies of buildings and structures with a pile foundation on an elastic foundation under seismic effects, $\mathbf{6}$, Questions of the dynamics of structures and the reliability of machines, pp. 36-40. Tashkent, (1990)

10. Adilkhodjaev A., Hasanov B., Shaumarov S., Kondrashchenko V. Aerated concrete with predetermined pore parameters for the exterior walls of energy efficient buildings, IOP Conference Series: Materials Science and Engineering, 1030(1), 012006, (2021)

11. Khasanov B., Vatin N., Mirzaev T., Suyunov A., Radjabov M. Analysis of the mode of squeezing out excess water for mixing concrete mixture in the process of peristaltic compaction, IOP Conference Series: Materials Science and Engineering, 1030(1), 01202, (12021)

12. Khasanov B., Vatin N., Mirzaev T., Suyunov A., Radjabov M. Physicochemical fundamentals of modifying concrete mix and concrete, IOP Conference Series: Materials Science and Engineering, 1030(1), 012022, (2021)

13. Khasanov B., Vatin N., Ismailova Z., Mirzaev T. Physical modification of concrete mix and concrete, IOP Conference Series: Materials Science and Engineering, 883(1), 012205, (2020)

14. Khasanov B., Irmuhamedova L., Firlina G., Mirzaev T. Theoretical foundations of the structure formation of cement stone and concrete, IOP Conference Series: Materials Science and Engineering, 869(3), 032032, (2020) 